\title{
The Effect of Work-Life Balance on Organizational Commitment of Accountants
}

\author{
CEM BERK \\ Istanbul Arel University, Turkey \\ cemberk@arel.edu.tr \\ FATIH GUNDOGMUS \\ Fe Auditing and Certified Public Accounting, Turkey \\ fatih@fedenetim.com
}

In today's working environments many people have a hard time to create a balance between work and personal life. Sustainable work environment policies that will ensure better work quality by giving people more time to research and a reasonable schedule have to be accepted. This research is unique in combining work life balance and organizational commitment. The motivation is that accountants work with an intense schedule and their commitment in work might be related to work life balance. The research includes a survey with the participation of 498 accountants working in Istanbul, Turkey. Based on the results the main hypothesis that there is a relationship between work life balance and organizational commitment is accepted. There are also differentiation analysis of work life balance and organizational commitment based on personal characteristics. In the research work life balance is explained with the variables, the effect of work to personal life, the effect of personal life to work, work life growth and the effect of working with husband/wife or other relative.

Key words: work-life balance, organizational commitment, accounting profession

https://doi.org/10.26493/1854-4231.13.137-159

\section{Introduction}

One of the main struggles of the accounting firms is organizational commitment. They fear that after a term of investment to the employee where he/she adapts and learns the job requirements, he/she can quit the job to start another career in another firm. Therefore, a good grasp of the underlying factors of organizational commitment is required for the accounting firms to create a desirable work environment. In accounting, the quality of people employed directly influences the output of the work. If the employees are not motivated 
or there is high turnover, there may be mistakes in the output which is likely to cause loss of money.

There are several studies with the focus of organizational commitment of accountants. However this research is unique because it combines work life balance with organizational commitment. Work life balance which is explained as the effect of personal life to work, the effect of work to personal life, work life growth, and the effect of working with husband/wife or other relative in this research may lead to organizational commitment. Moreover there are differentiation analyses of work life balance and organizational commitment based on personal characteristics.

Some selected findings from the research can be mentioned here. According to the research results, work-life balance lead to organizational commitment of employees. Therefore, maintaining worklife balance in the work environment is crucial for organizational of accountants in Istanbul. There are several critical groups that have work-life balance problem. Those with two children, middle income, 29 or less clients, and 25 years and more occupational experience have more work-life balance problem. And some groups are also critical in organizational commitment. Those are accountants with one child or three or more children, low income, 30-35 and 46 and more age groups. Work-life balance improvements can be made with a focus on critical groups that are found in this research.

The remainder of the paper is organized as follows. The second section gives a brief summary of the important works in the literature. The third section describes the methodology and introduces the frequencies of the survey. The fourth section includes three subchapters, testing the main hypothesis, differentiation analysis of the work life balance and differentiation analysis of organizational commitment. In the fifth section, a general discussion on the results is provided. The sixth section includes final remarks of the paper.

\section{Literature Review}

THEORETICAL FOUNDATION FOR WORK-LIFE BALANCE

Balven et al. (2018) describe work-life balance as organizational support for aspects of employees' personal life such as flexible work hours, dependent care and family/personal leave. Therefore it requires the interaction of organizational factors with personal factors. Most seen practices include family leave programs, job sharing and on site children care.

Nizam and Kam (2018) measured the determinants of work-life 
balance with a survey in the event industry of Malaysia. The significant variables are working hours, work load, work arrangements and reward schemes. Leave policies are not significant in this research.

Oludayo et al. (2018) investigate the relationship between worklife balance and employee behavioural outcomes. The research is based on a survey in some selected commercial banks in Nigeria. Results show that work leave arrangement, employee time out, employee social support, and dependent care initiative are predictors of employee behaviour outcomes.

Haider, Jabeen, and Ahmad (2018) also made a survey in the banking sector. The commercial banks are based in Pakistan. By using a mediation model the authors answer why work-life balance affects employee job performance. According to the results employees' satisfaction with corkers' increase psychological wellbeing, strengthening work-life balance.

Braun and Peus (2018) study the effect of authentic leadership on work life balance. The correlation analyses results indicate that authentic relationship significantly influences leaders' and followers' work life balance and followers' job satisfaction. There is also a positive correlation between leaders' and followers' work-life balance and followers' job satisfaction. Leader-member exchange is also positively correlated with leaders' and followers' work-life balance.

\section{THEORETICAL FOUNDATION FOR ORGANIZATIONAL COMMITMENT}

According to Ahuja, Padhy, and Srivastava (2018) there are many factors that affect organizational commitment. Individual factors are age and tenure, gender, education, employment alternatives, sense of competence, and internal control. Organizational factors include perceived structure, process, and climate, job satisfaction, organizational culture, organizational socialization, person-organization fit, and role conflict and organization citizenship behaviour.

Celis (2018) defines organizational commitment as individual's psychological attachment to the organization. According to the researcher organizational commitment also positively affects regulatory compliance. The research is based on qualitative and quantitative techniques including a case study and statistical analysis with a focus on Electronic Commerce Act in Philippines.

According to Aksoy, Sengun, and Yllmaz (2018) an important task for the companies is to ensure psychological and social satisfaction of the employees. Therefore it is important to attract the employees to make them stay in the organization. This would increase the ef- 
ficiency and the profitability of the company. The motivations of the employees also increase in an organization with high commitment.

Lapointe and Vandenberghe (2018) argue that there is a relationship between servant leadership and organizational commitment. And it might affect employee behaviours. They find out using Data from Canadian service industry that service leadership predicts employee's effective, normative and perceived sacrifice commitment.

Ayodtun et al. (2018) investigate the relationship between a tasktrait oriented leadership type and organizational commitment. The results show that leadership has a significant effect on employee commitment. Therefore leadership types might be influenced by organizational factors. The research is based on a questionnaire that took place in five leading banks of Nigeria.

\section{SIMILAR STUDIES}

Aryee, Wyatt, and Min (1990) surveyed 245 professional accountants in Singapore. The goal of the research is to understand which factors lead to turnover and organizational commitment. The results indicate that companies that allow employees to develop and share their professional values and behaviour gain more professionalorganizational commitment.

Gregson (1992) researched on the order of job satisfaction and commitment in accounting. There are different assumptions in the literature considering which one is the antecedent. The model in which the satisfaction is antecedent to commitment is more efficient in predicting turnover.

Ketchand and Strawser (2001) study organizational commitment in accounting research. An important aspect is to find out which factors motivate accountants to stay in the firm. It is also interesting to know how much formal efforts by the company do lead to organizational commitment. One particular case is the effect of mentoring on organizational commitment.

Bloom and Cenker (2005) focus on importance of commitments in accounting recruitments. They provide a case that can be discussed in undergraduate accounting education. The case is about a student who accepted an employment offer prior to graduation from accounting department. However, as a senior student he works part time in another company and decides to work with them following graduation. They try to bring the emphasis of organizational commitment during recruitment stage to the accounting curriculum.

Nasina and Doris (2011) researched on workplace spirituality in big four public accounting firms in Malaysia. 153 people responded

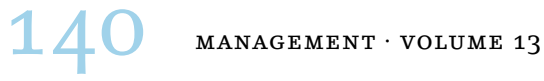


to a questionnaire. The methodology used is a multiple regression analysis. The results show that organizational affective commitment is influenced by the team's sense of community, sense of contribution to the society and enjoyment at work.

Herda and Lavelle (2013) studied auditors' commitment to the clients. The research is based on a survey completed by 204 auditors. One interesting finding is perceived fairness results in perceived support by client, and perceived support lead to auditor commitment. Higher commitment leads to better service which is more than fundamental requirements of audit service.

Cetin, Kizil, and Zengin (2013) made a survey for 90 accounting and finance professionals in Turkey. The study is concentrated on the effect of mentoring on organizational commitment and job satisfaction. According to their continuance commitment model, all variables of mentoring (career development, role modelling and social support) and control variables (gender and age) are all statistically significant individually.

McManus and Subramaniam (2014) focused on early career accountants. A survey of 56 people was made to see the relationship between mentoring and organizational ethical climate and professional commitment. The results show that career development style of mentoring does lead to organizational commitment. There is also a positive correlation between organizational ethical climate and commitment.

Church (2014) worked on assimilation of accounting recruits in public accounting firms. A qualitative approach is applied to current and former employees. Accordingly most challenges arise due to differences in new hires' qualities and prior experiences versus the nature of first year work, college schedules versus work schedules, college reward systems versus public accounting reward systems, and the recruiting environment versus the work environment.

Cannon and Herda (2016) replicate Herda and Lavalle (2013) study to see its robustness. They use an alternative measure of commitment called кUт. All predicted relationships are supported which shows the reliability of Herda and Lavalle and their measure of commitment.

Hart, Kremin, and Pasewark (2017) worked on 127 audit interns to find out the change in commitment following internship experience. The results reveal that due to high workload, both organizational and professional commitment declines. However offering challenging work experience and opportunity to work with desirable colleagues increases the commitment. 


\section{Research Methodology}

RESEARCH GOAL

The goal of this research is to find out the relationship between work life balance and organizational commitment among accountants. Work life balance is also analysed with the independent variables; the effect of personal life to work, the effect of work to personal life, work-life growth, and the effect of working with husband/wife or other relative.

The major hypothesis for this research is given below.

$\mathrm{H} 1$ There is a significant relationship between work-life balance and organizational commitment.

Another goal is to find out how personal factors affect work-life balance and level of organizational commitment. The personal factors used in the study are number of children, income, number of clients, taking mental therapy and occupational experience.

\section{RESEARCH FREQUENCIES}

A survey is conducted for certified public accountants working in Istanbul, Turkey. The total number of certified public accountants is 38.476. The number of respondents is 498 . Table 1 shows frequencies and percentages of the survey.

SAMPLING

The research universe is certified public accountants working in Istanbul Turkey. By the time of the research there are 38.676 registered accountants in Istanbul Chamber of Certified Public Accountants. This is taken as the research universe. Because of the high number of members and due to budget and time constraints, sampling is applied in this research.

Simple random sampling method is used in this study. To find the size of the sample which represents the universe the following formula has been used (Karasar 2014):

$$
n=\frac{N t^{2} p q}{d^{2}(N-1)}+t^{2} p q,
$$

where $N$ is the number of individuals in the target universe (38676 accountants), $n$ is the number of individuals in the sample, $p$ is the probability of the event occurrence (o.9), $q$ is the probability of the event non-occurrence (0.1), $t$ is theoretical value taken from $t$ table in a specified level of significance (sampling error $5 \%$ - table value is 1.96), $d$ is the sampling error (0.05).

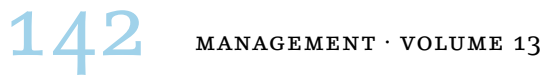


TABLE 1 Frequencies of the Survey

\begin{tabular}{|c|c|c|c|}
\hline Category & Group & (1) & (2) \\
\hline \multirow[t]{2}{*}{ Gender } & Female & 219 & 44.0 \\
\hline & Male & 279 & 56.0 \\
\hline \multirow[t]{5}{*}{ Age } & 29 or less & 24 & 4.8 \\
\hline & $30-35$ & 192 & 38.6 \\
\hline & $36-45$ & 192 & 38.6 \\
\hline & $46-55$ & 66 & $13 \cdot 3$ \\
\hline & 56 and more & 24 & 4.8 \\
\hline \multirow[t]{4}{*}{ Level of Education } & High School & 57 & 11.4 \\
\hline & Vocational & 30 & 6.0 \\
\hline & University & 312 & 62.7 \\
\hline & Master's or higher & 99 & 19.9 \\
\hline \multirow[t]{2}{*}{ Marital Status } & Married & 303 & 60.8 \\
\hline & Single & 195 & 39.2 \\
\hline \multirow[t]{4}{*}{ Level of Income } & $\mathrm{O}-2500 \mathrm{TL}$ & 60 & 12.0 \\
\hline & $2501-4000 \mathrm{TL}$ & 102 & 20.5 \\
\hline & 4001-6000 TL & 144 & 28.9 \\
\hline & $6001 \mathrm{TL}$ or more & 192 & 38.6 \\
\hline \multirow[t]{4}{*}{ Number of Children } & None & 207 & 41.6 \\
\hline & 1 & 96 & $19 \cdot 3$ \\
\hline & 2 & 153 & 30.7 \\
\hline & 3 & 42 & 8.4 \\
\hline \multirow[t]{5}{*}{ Number of Clients } & 29 or less & 243 & 48.8 \\
\hline & $30-35$ & 42 & 8.4 \\
\hline & $36-45$ & 54 & 10.8 \\
\hline & $46-55$ & 27 & $5 \cdot 4$ \\
\hline & 56 or more & 132 & 26.5 \\
\hline \multirow[t]{2}{*}{ Taking Mental Therapy } & Yes & 51 & 10.2 \\
\hline & No & 447 & 89.8 \\
\hline \multirow[t]{5}{*}{ Occupational Experience } & $1-5$ years & 105 & 21.1 \\
\hline & $6-11$ years & 105 & 21.1 \\
\hline & $12-17$ years & 120 & 24.1 \\
\hline & $18-24$ years & 84 & 16.9 \\
\hline & 25 years and more & 84 & 16.9 \\
\hline
\end{tabular}

NотеS Column headings are as follows: (1) frequency, (2) percentage.

By using the formula with $5 \%$ sampling error, the sampling size is calculated as $n=380$.

1.000 surveys has been distributed to reach minimum sample size that represent the universe. The completed surveys that is suitable 
fort he analysis is 498. These surveys are chosen as the research sample for this study.

DATA COLLECTION

A questionnaire is used in this research. The questionnaire is organized in 3 parts. These parts are work-life balance, organizational commitment and personal information. Academic background for each of the parts is provided in the subchapters below.

\section{Academic Background for Work-Life Balance}

In the research, the survey scale used for work-life balance is taken from a completed doctoral dissertation. The title of the dissertation The influence of work life balance on the quality of work life in tourism industries. The study is made by Deniz Küçükusta (2007).

In the scale, there are 15 expressions. Some selected expressions are 'I neglect my personal life due to my work,' 'My personal life take the energy required for my work,' and 'The responsibilities in my personal life affects work.'

The scale has four factors. These factors are the effect of personal life to work, the effect of work to personal life, work-life balance and the effect of working with husband/wife or other relative.

In the reliability analysis Cronbach Alpha coefficients are computed as 0.907 for the effect of personal life to work, 0.924 for the effect of work to personal life, 0.892 for work-life balance and 0.876 for the effect of working with husband/wife or other relative (Küçükusta 2007). As all of the coefficients are more than 0.8 , the scale has high reliability (Karasar 2014).

\section{Academic Background for Organizational Commitment}

The survey scale used in this research for organizational commitment was developed by Kanungo (1982) and later applied in Turkish by Kartal (2015).

The scale has 10 articles and one factor. In the reliability analysis the Cronbach Alpha for organizational commitment in this research is computed as 0.887 . Therefore, the scale has high reliability (Karasar, 2014).

\section{Personal Information}

This part of the questionnaire is developed for this research. It consists of 8 questions. These questions are age, level of education, marital status, number of children, level of income, number of clients,

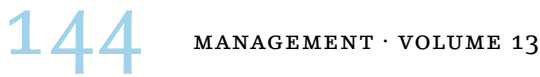


TABLE 2 Descriptive Statistics for the Research Scales

\begin{tabular}{lrrrrr}
\hline Item & $(1)$ & $(2)$ & $(3)$ & $(4)$ & $(5)$ \\
\hline $\begin{array}{l}\text { The effect of personal life to } \\
\text { work }\end{array}$ & 498 & 1.00 & 5.00 & 3.5506 & 0.96950 \\
$\begin{array}{l}\text { The effect of work to personal } \\
\text { life }\end{array}$ & 498 & 1.00 & 5.00 & 2.9127 & 0.97692 \\
$\begin{array}{l}\text { Work-life growth } \\
\text { The effect of working with hus- }\end{array}$ & 498 & 1.00 & 5.00 & 3.1175 & 0.93622 \\
band/wife or other relative & 498 & 1.00 & 5.00 & 2.8795 & 1.16044 \\
Organizational commitment & 498 & 1.00 & 5.00 & 2.9000 & 0.65998 \\
\hline
\end{tabular}

notes Column headings are as follows: (1) $N$, (2) min, (3) max, (4) mean, (5) standard deviation.

taking mental therapy and occupational experience. This is also the exact order of the questions available in the questionnaire.

\section{Descriptive Statistics for the Scales}

The average for the effect of personal life to work, the effect of work to personal life, work life growth, the effect of working with husband/wife or other relative and organizational commitment are respectively $3.55 \pm 0.96,2.91 \pm 0.97,3.11 \pm 0.93,2.87 \pm 1.16$, and $2.90 \pm 0$. These statistics are presented in table 2 .

\section{RESEARCH TECHNIQUE}

\section{Methodology for the Main Hypothesis}

A software package (spss 23) is used in the analysis. Variables are tested in correlation analysis to check the relationship between the variables. Regression analysis is made in the research. When independent two groups are compared, $t$-test is used. However, when three and more groups are compared Anova and Tukey Test as a Post Hoc test has been used. The findings are evaluated under $5 \%$ level of significance.

The regression analysis is made to test the hypothesis effectively. Several reliability tests are made to check the reliability of the model. Some of these tests are given below. The type of regression is multiple linear regression which is adequate to show the relationship between organizational commitment and variables that represent work-life balance. The model is formulated as below.

Organizational commitment $=c+\beta 1 \times$ the effect of personal life to work $+\beta 2 \times$ the effect of work to personal life $+\beta 3 \times$ work-life growth $+\beta_{4} \times$ the effect of working with husband/wife or other relative $+\varepsilon$. 
TABLE 3 Correlation Table among Scales

\begin{tabular}{|c|c|c|c|c|c|}
\hline Item & (1) & $(2)$ & (3) & (4) & (5) \\
\hline (1) The effect of personal life to work & & $0.358^{* *}$ & 0.032 & $0.183^{* *}$ & $-0.147^{* *}$ \\
\hline (2) The effect of work to personal life & & & $0.101 *$ & $0.224^{* *}$ & $-0.246^{* *}$ \\
\hline (3) Work-life growth & & & & $-0.154^{* *}$ & $0.254^{* *}$ \\
\hline \multirow{2}{*}{\multicolumn{4}{|c|}{$\begin{array}{l}\text { (4) The effect of working with husband/wife or other relative } \\
\text { (5) Organizational commitment }\end{array}$}} & & $-0.130^{* *}$ \\
\hline & & & & & \\
\hline
\end{tabular}

NOTES * significant under $5 \%$ level of significance, ${ }^{* *}$ significant under $1 \%$ level of significance.

TABLE 4 Normality Test Results

\begin{tabular}{lrr}
\hline Item & $(1)$ & $(2)$ \\
\hline The effect of personal life to work & -1.327 & 1.422 \\
The effect of work to personal life & -0.537 & -0.816 \\
Work-life growth & -0.489 & -1.386 \\
The effect of working with husband/wife or other relative & -0.086 & -0.579 \\
Organizational Commitment & -0.769 & -0.516 \\
\hline
\end{tabular}

Notes Column headings are as follows: (1) skewness, (2) kurtosis.

The relationships between the variables are tested with Pearson correlation analysis. The direction of the relationship is available with the sign of the coefficient. As a conclusion of the analysis, all relationships are very weak. This is required for a reliable research. The results are given in table 3 .

\section{Methodology for the Differentiation Analysis}

To determine the methodology suitable for the differentiation analysis, normality test is applied. The results are provided in table 4 .

According to Tabachnick, Fidell, and Osterlind (2013), skewness and kurtosis values between +1.5 and -1.5 show that the data is normally distributed. Similarly George and Mallery (2010) argue that for normal distribution skewness and kurtosis values should be between +2.0 and -2.0 . According to this information from literature, the data is normally distributed for all of the sub scales. The data is within the range suggested by both of the works from the literature.

Because of this, the data is eligible for parametric tests. For the differentiation analysis $t$-test and ANOva are used.

\section{Results}

TESTING THE MAIN HYPOTHESIS

The main hypothesis of the research is that there is a statistically significant relationship between work life balance and organizational

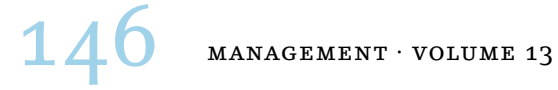


TABLE 5 The Effect of Work Life Balance on Organizational Commitment

\begin{tabular}{lrrrrrr}
\hline Independent Variable & $\beta$ & $t$ & $p$ & $F$ & $p$ & $R^{2}$ \\
\hline Constant & 2.962 & 19.156 & 0.000 & 20.615 & 0.000 & 0.143 \\
The effect of personal & -0.044 & -1.439 & 0.151 & & & \\
life to work & & & & & \\
The effect of work to & -0.166 & -5.338 & 0.000 & & \\
personal life & & & & & \\
Work-life Growth & 0.196 & 6.525 & 0.000 & & \\
$\begin{array}{l}\text { The effect of working } \\
\text { with husband/wife or other relative }\end{array}$ & -0.011 & -0.449 & 0.654 & & & \\
\hline
\end{tabular}

TABLE 6 The Differentiation of Work-Life Balance Based on Number of Children

\begin{tabular}{|c|c|c|c|c|c|c|c|}
\hline \multicolumn{2}{|c|}{ Variable/group } & \multirow{2}{*}{$\frac{(1)}{207}$} & \multirow{2}{*}{$\frac{(2)}{3.6029}$} & \multirow{2}{*}{$\frac{(3)}{0.99014}$} & \multirow{2}{*}{$\frac{(4)}{1.013}$} & \multirow{2}{*}{$\frac{(5)}{0.386}$} & \multirow[t]{2}{*}{ (6) } \\
\hline (a) & None & & & & & & \\
\hline & 1 & 96 & 3.6250 & 1.09400 & & & \\
\hline & 2 & 153 & 3.4706 & 0.93259 & & & \\
\hline & 3 & 42 & 3.4143 & 0.63306 & & & \\
\hline & Total & 498 & 3.5056 & 0.96950 & & & \\
\hline \multirow[t]{5}{*}{ (b) } & None & 207 & 2.7790 & 1.01195 & 2.244 & 0.082 & \\
\hline & 1 & 96 & 2.9922 & 1.03138 & & & \\
\hline & 2 & 153 & 3.0196 & 0.88831 & & & \\
\hline & 3 & 42 & 3.0000 & 0.93704 & & & \\
\hline & Total & 498 & 2.9127 & 0.97692 & & & \\
\hline \multirow[t]{5}{*}{ (c) } & None & 207 & 2.9964 & 1.00920 & 2.738 & 0.043 & $3>1$ \\
\hline & 1 & 96 & 3.1563 & 0.96672 & & & \\
\hline & 2 & 153 & 3.2745 & 0.83743 & & & \\
\hline & 3 & 42 & 3.0536 & 0.75413 & & & \\
\hline & Total & 498 & 3.1175 & 0.93622 & & & \\
\hline \multirow[t]{5}{*}{ (d) } & None & 207 & 2.9420 & 1.04697 & 0.732 & 0.533 & \\
\hline & 1 & 96 & 2.8125 & 1.29218 & & & \\
\hline & 2 & 153 & 2.8922 & 1.25386 & & & \\
\hline & 3 & 42 & 2.6786 & 1.02304 & & & \\
\hline & Total & 498 & 2.8795 & 1.16044 & & & \\
\hline
\end{tabular}

Notes Column/row headings are as follows: (1) $n$, (2) mean, (3) standard deviation, (4) $F$, (5) $p$, (6) difference, (a) the effect of personal life to work, (b) the effect of work to personal life, (c) work-life growth, (d) the effect of working with husband/wife or other relative.

commitment. Work life balance explains $14.3 \%$ of the variance of organizational commitment. The contribution of work life balance to the variance is significant ( $p=0.000, F=20.615$ ). Therefore, an evaluation of the results indicate that the main hypothesis $\mathrm{H} 1$ is accepted. 
TABLE 7 The Differentiation of Work-Life Balance Based on Income

\begin{tabular}{|c|c|c|c|c|c|c|c|}
\hline \multicolumn{2}{|c|}{ Variable/group } & (1) & (2) & (3) & (4) & (5) & (6) \\
\hline \multirow[t]{5}{*}{ (a) } & $\mathrm{O}-2500 \mathrm{TL}$ & 60 & 3.4800 & 0.84709 & 4.406 & 0.005 & $3>2$ \\
\hline & $2501-4000 \mathrm{TL}$ & 102 & 3.2706 & 1.03738 & & & \\
\hline & 4001-6000 TL & 144 & 3.7000 & 0.95464 & & & $4>2$ \\
\hline & $6001 \mathrm{TL}$ and more & 192 & 3.6094 & 0.95343 & & & \\
\hline & Total & 498 & 3.5506 & 0.96950 & & & \\
\hline \multirow[t]{5}{*}{ (b) } & $\mathrm{O}-2500 \mathrm{TL}$ & 60 & 2.6875 & 1.02058 & 2.946 & 0.033 & $3>1$ \\
\hline & $2501-4000 \mathrm{TL}$ & 102 & 2.9412 & 1.07984 & & & \\
\hline & 4001-6000 TL & 144 & 3.0833 & 0.91939 & & & $3>4$ \\
\hline & 6001 TL and more & 192 & 2.8398 & o. 93195 & & & \\
\hline & Total & 498 & 2.9127 & 0.97692 & & & \\
\hline \multirow[t]{5}{*}{ (c) } & $\mathrm{O}-2500 \mathrm{TL}$ & 60 & 3.2625 & 0.95827 & 3.094 & 0.027 & $1>2$ \\
\hline & $2501-4000 \mathrm{TL}$ & 102 & 2.8750 & 1.01092 & & & \\
\hline & 4001-6000 TL & 144 & 3.1719 & 0.91771 & & & $3>2$ \\
\hline & $6001 \mathrm{TL}$ and more & 192 & 3.1602 & 0.88549 & & & \\
\hline & Total & 498 & 3.1175 & o. 93622 & & & $4>2$ \\
\hline \multirow[t]{5}{*}{ (d) } & $0-2500 \mathrm{TL}$ & 60 & 3.0500 & 1.09196 & 3.452 & 0.016 & $1>4$ \\
\hline & $2501-4000 \mathrm{TL}$ & 102 & 3.0294 & 1.18117 & & & \\
\hline & 4001-6000 TL & 144 & 2.9792 & 1.21165 & & & $2>4$ \\
\hline & $6001 \mathrm{TL}$ and more & 192 & 2.6719 & 1.10763 & & & \\
\hline & Total & 498 & 2.8795 & 1.16044 & & & $3>4$ \\
\hline
\end{tabular}

Nотеs Column/row headings are as follows: (1) $n$, (2) mean, (3) standard deviation, (4) $F$, (5) $p$, (6) difference, (a) the effect of personal life to work, (b) the effect of work to personal life, (c) work-life growth, (d) the effect of working with husband/wife or other relative.

The independent variables can also be evaluated individually. The effect of personal life to work doesn't statistically affect organizational commitment $(p=0.151>0.05)$ The effect of work to personal life lowers organizational commitment $(\beta=-0.166)$. Work life balance increases organizational commitment $(\beta=0.196)$. The effect of working with husband/wife or other relative doesn't statistically affect organizational commitment $(p=0.654>0.05)$.

\section{DIFFERENTIATION ANALYSIS OF WORK-LIFE BALANCE}

The differentiation of the subfactors of work life balance based on personal characteristics of the respondents are tabulated and presented based on characteristics. Table 6 shows that work life balance differentiates based on number of children. In work life growth, the average of accountants with 2 children is significantly higher than accountants with no children. 
TABLE 8 The Differentiation of Work-Life Balance Based on Number of Clients

\begin{tabular}{|c|c|c|c|c|c|c|c|}
\hline \multicolumn{2}{|c|}{ Variable/group } & \multirow{2}{*}{$\frac{(1)}{243}$} & \multirow{2}{*}{$\frac{(2)}{3.6000}$} & \multirow{2}{*}{$\frac{(3)}{0.94947}$} & \multirow{2}{*}{$\frac{(4)}{1.458}$} & \multirow{2}{*}{$\frac{(5)}{0.214}$} & \multirow[t]{2}{*}{ (6) } \\
\hline (a) & 29 or less & & & & & & \\
\hline & $30-35$ & 42 & $3 \cdot 3286$ & 0.94205 & & & \\
\hline & $36-45$ & 54 & 3.5444 & 1.00220 & & & \\
\hline & $46-55$ & 27 & 3.2444 & 0.98813 & & & \\
\hline & 56 and more & 132 & 3.5955 & 0.99048 & & & \\
\hline & Total & 498 & 3.5506 & 0.96950 & & & \\
\hline \multirow[t]{6}{*}{ (b) } & 29 or less & 243 & 3.0556 & 0.98333 & 4.755 & 0.001 & $1>2$ \\
\hline & $30-35$ & 42 & 2.5357 & 0.84386 & & & \\
\hline & $36-45$ & 54 & 3.0000 & 0.88622 & & & $1>4$ \\
\hline & $46-55$ & 27 & 2.4722 & 0.86972 & & & \\
\hline & 56 and more & 132 & 2.8239 & 1. 00464 & & & $1>5$ \\
\hline & Total & 498 & 2.9127 & 0.97692 & & & \\
\hline \multirow[t]{6}{*}{ (c) } & 29 or less & 243 & 3.1852 & 0.91541 & 1.705 & 0.148 & \\
\hline & $30-35$ & 42 & 3.2679 & 1.04967 & & & \\
\hline & $36-45$ & 54 & 3.1389 & 0.99606 & & & \\
\hline & $46-55$ & 27 & 3.0556 & 0.81256 & & & \\
\hline & 56 and more & 132 & 2.9489 & 0.92451 & & & \\
\hline & Total & 498 & 3.1175 & o. 93622 & & & \\
\hline \multirow[t]{6}{*}{ (d) } & 29 or less & 243 & 3.0494 & 1.08122 & 16.046 & 0.000 & $1>2$ \\
\hline & $30-35$ & 42 & 1.6071 & $0.8155^{2}$ & & & \\
\hline & $36-45$ & 54 & 2.8333 & 0.84116 & & & $3>2$ \\
\hline & $46-55$ & 27 & 2.8333 & 1.12660 & & & \\
\hline & 56 and more & 132 & 3.0000 & 1.27063 & & & $4>2$ \\
\hline & Total & 498 & 2.8795 & 1.16044 & & & $5>2$ \\
\hline
\end{tabular}

Notes Column/row headings are as follows: (1) $n$, (2) mean, (3) standard deviation, (4) $F$, (5) $p$, (6) difference, (a) the effect of personal life to work, (b) the effect of work to personal life, (c) work-life growth, (d) the effect of working with husband/wife or other relative.

The differentiation analysis of work life balance based on income is presented table 7. Accordingly, the effect of personal life to work, the effect of work to personal life, work-life growth, and the effect of working with husband/wife or other relative differentiate based on income. In all of the subfactors the level of income group 4001-60oo TL is significantly higher than one or more other groups.

The differentiation analysis of work life balance based on number of clients is given in table 8. Accordingly the effect of work to personal life and the effect of working with husband/wife or other relative differentiate based on number of clients. However the effect of personal life to work and work life balance doesn't differen- 
TABLE 9 The Differentiation of Work-Life Balance Based on Taking Mental Therapy

\begin{tabular}{llrrrrr}
\hline \multicolumn{2}{l}{ Variable/group } & $(1)$ & $(2)$ & $(3)$ & $(4)$ & (5) \\
\hline (a) & Yes & 51 & 3.4118 & 1.09648 & 1.436 & 0.231 \\
& No & 447 & 3.5664 & 0.95403 & & \\
\hline (b) & Yes & 51 & 2.6618 & 0.92036 & 0.160 & 0.689 \\
& No & 447 & 2.9413 & 0.98007 & & \\
\hline (c) & Yes & 51 & 2.8235 & 0.84749 & 0.697 & 0.404 \\
& No & 447 & 3.1510 & 0.94086 & & \\
\hline (d) & Yes & 51 & 2.7353 & 0.83278 & 8.092 & 0.219 \\
& No & 447 & 2.8960 & 1.19172 & & \\
\hline
\end{tabular}

Notes Column/row headings are as follows: (1) n, (2) mean, (3) standard deviation, (4) $F$, (5) $p$, (a) the effect of personal life to work, (b) the effect of work to personal life, (c) work-life growth, (d) the effect of working with husband/wife or other relative.

tiate based on number of clients. The results also reveal that number of clients group 29 or less has higher mean than most of the other number of clients groups. Also 30-35 number of clients group has the lowest average statistically in the effect of working with husband/wife or other relative.

Table 9 shows the details of the findings in the differentiation of work-life balance based on taking mental therapy. The results show that the subdimensions of the work life balance which are the effect of personal life to work, the effect of work to personal life, work-life growth and the effect of working with husband/wife or other relative don't differentiate based on taking mental therapy.

Finally the differentiation of work life balance based on occupational experiences is explained in table 10. Accordingly the effect of personal life to work and work life growth differentiate based on occupational experience. However the effect of work to personal life and the effect of working with husband/wife or other relative don't differentiate. Accordingly within the subfactors that differentiate the occupational experience group, 25 years and more has statistically higher mean than two other occupational experience groups.

DIFFERENTIATION ANALYSIS OF ORGANIZATIONAL COMMITMENT

The differentiation of organizational commitment based on personal characteristics are tabulated and presented separately for each personal characteristic. The personal characteristics that are used in this research are number of children, level of income, number of clients, taking mental therapy and occupational experience.

Table 11 indicates the differentiation of organizational commit- 
TABLE 10 The Differentiation of Work-Life Balance Based on Occupational Experience

\begin{tabular}{|c|c|c|c|c|c|c|c|}
\hline \multicolumn{2}{|c|}{ Variable/group } & \multirow{2}{*}{$\frac{(1)}{105}$} & \multirow{2}{*}{$\frac{(2)}{3 \cdot 3543}$} & \multirow{2}{*}{$\frac{(3)}{1.00202}$} & \multirow{2}{*}{$\frac{(4)}{2.760}$} & \multirow{2}{*}{$\frac{(5)}{0.027}$} & \multirow{2}{*}{$\frac{(6)}{2>1}$} \\
\hline (a) & 1-5 years & & & & & & \\
\hline & 6-11 years & 105 & 3.6343 & 0.85596 & & & \\
\hline & 12-17 years & 120 & 3.5800 & 0.98881 & & & $5>1$ \\
\hline & 18-24 years & 84 & $3 \cdot 4286$ & 1.09242 & & & \\
\hline & 25 years and more & 84 & $3 \cdot 7714$ & 0.85652 & & & $5>4$ \\
\hline & Total & 498 & 3.5506 & 0.96950 & & & \\
\hline \multirow[t]{6}{*}{ (b) } & 1-5 years & 105 & 2.8429 & 0.95150 & 1.703 & 0.148 & \\
\hline & 6-11 years & 105 & 2.7929 & 0.92147 & & & \\
\hline & 12-17 years & 120 & 3.0563 & 1.07759 & & & \\
\hline & 18-24 years & 84 & 2.8214 & 0.94069 & & & \\
\hline & 25 years and more & 84 & 3.0357 & 0.94275 & & & \\
\hline & Total & 498 & 2.9127 & 0.97692 & & & \\
\hline \multirow[t]{6}{*}{ (c) } & 1-5 years & 105 & $3 \cdot 3214$ & 0.91968 & 3.670 & 0.006 & $1>2$ \\
\hline & 6-11 years & 105 & 2.9143 & 0.80326 & & & \\
\hline & 12-17 years & 120 & 3.1063 & 1.01494 & & & $1>4$ \\
\hline & 18-24 years & 84 & 2.9732 & 0.99775 & & & \\
\hline & 25 years and more & 84 & 3.2768 & 0.86951 & & & $5>2$ \\
\hline & Total & 498 & 3.1175 & 0.93622 & & & $5>4$ \\
\hline \multirow[t]{6}{*}{ (d) } & 1-5 years & 105 & 2.7857 & 1.08941 & 0.962 & 0.428 & \\
\hline & 6-11 years & 105 & 2.7857 & 1.12202 & & & \\
\hline & 12-17 years & 120 & 3.0375 & 1.11363 & & & \\
\hline & 18-24 years & 84 & 2.9286 & 1.23733 & & & \\
\hline & 25 years and more & 84 & 2.8393 & 1.27572 & & & \\
\hline & Total & 498 & 2.8795 & 1.16044 & & & \\
\hline
\end{tabular}

Notes Column/row headings are as follows: (1) $n$, (2) mean, (3) standard deviation, (4) $F$, (5) $p$, (6) difference, (a) the effect of personal life to work, (b) the effect of work to personal life, (c) work-life growth, (d) the effect of working with husband/wife or other relative.

TABLE 11 The Differentiation of Organizational Commitment Based on Number of Children

\begin{tabular}{|c|c|c|c|c|c|c|}
\hline Number of children & (1) & (2) & (3) & (4) & (5) & (6) \\
\hline None & 207 & 3.0116 & 0.71466 & 10.405 & 0.000 & $1>2$ \\
\hline 1 & 96 & 2.6344 & 0.65129 & & & $1>4$ \\
\hline 2 & 153 & 2.9824 & 0.58153 & & & $3>2$ \\
\hline 3 or more & 42 & 2.6571 & 0.40433 & & & $3>4$ \\
\hline Total & 498 & 2.9000 & 0.65998 & & & \\
\hline
\end{tabular}

Notes Column headings are as follows: (1) $n$, (2) mean, (3) standard deviation, (4) $F$, (5) $p,(6)$ difference. 
TABLE 12 The Differentiation of Organizational Commitment Based on Income

\begin{tabular}{lrrrrrr}
\hline Income & $(1)$ & $(2)$ & $(3)$ & $(4)$ & $(5)$ & $(6)$ \\
\hline 0-2500 TL & 60 & 3.0500 & 0.49341 & 3.174 & 0.024 & \\
$2501-4000 \mathrm{TL}$ & 102 & 3.0294 & 0.62578 & & & $2>3$ \\
$4001-6000 \mathrm{TL}$ & 144 & 2.9792 & 0.71400 & & & \\
6001 TL and more & 192 & 2.6719 & 0.66934 & & & $2>4$ \\
Total & 498 & 2.8795 & 0.65998 & & & \\
\hline
\end{tabular}

NотеS Column headings are as follows: (1) $n$, (2) mean, (3) standard deviation, (4) $F$, (5) $p,(6)$ difference.

TABLE 13 The Differentiation of Organizational Commitment Based on Number of Clients

\begin{tabular}{lrrrrrr}
\hline Number of clients & $(1)$ & $(2)$ & $(3)$ & $(4)$ & $(5)$ & $(6)$ \\
\hline 29 or less & 243 & 2.8383 & 0.66796 & 4.552 & 0.001 & $2>1$ \\
$30-35$ & 42 & 3.0786 & 0.59777 & & & $2>3$ \\
$36-45$ & 54 & 2.6833 & 0.76003 & & & $4>1$ \\
$46-55$ & 27 & 3.1556 & 0.67615 & & & $4>3$ \\
56 and more & 132 & 2.9932 & 0.57720 & & & $5>1$ \\
Total & 498 & 2.9000 & 0.65998 & & & $5>3$ \\
\hline
\end{tabular}

Notes Column headings are as follows: (1) $n,(2)$ mean, (3) standard deviation, (4) $F$, (5) $p$, (6) difference.

ment based on number of children. The findings reveal that respondents with no children and two children have statistically higher average than two other number of children groups.

In table 12, the differentiation of organizational commitment based on income is given. According to the results, 2501-4000 TL income group statistically differentiates from 4001-6000 TL and 6001 TL and more income groups.

The differentiation of organizational commitment based on number of clients is given in table 13 . The results show that 30-35, 46-55 and 56 and more number of clients groups statistically differentiates from two other number of clients groups.

Table 14 shows the differentiation of organizational commitment

TABLE 14 The Differentiation of Organizational Commitment Based on Taking Mental Therapy

\begin{tabular}{lrrrrr}
\hline Taking mental therapy & $(1)$ & $(2)$ & $(3)$ & $(4)$ & (5) \\
\hline Yes & 51 & 2.8176 & 0.55882 & 2.032 & 0.115 \\
No & 447 & 2.9094 & 0.67045 & & \\
\hline
\end{tabular}

NотеS Column headings are as follows: (1) $n$, (2) mean, (3) standard deviation, (4) $F$, (5) $p$. 
TABLE 15 The Differentiation of Organizational Commitment Based on Occupational Experience

\begin{tabular}{lrrrrr}
\hline Occupational experience & $(1)$ & $(2)$ & $(3)$ & $(4)$ & (5) \\
\hline 1-5 years & 105 & 2.9457 & 0.65310 & 1.846 & 0.119 \\
6-11 years & 105 & 2.8257 & 0.60781 & & \\
12-17 years & 120 & 3.0175 & 0.70218 & & \\
18-24 years & 84 & 2.8286 & 0.73083 & & \\
25 years and more & 84 & 2.8393 & 0.57561 & & \\
Total & 498 & 2.9000 & 0.65998 & & \\
\hline
\end{tabular}

Notes Column headings are as follows: (1) $n$, (2) mean, (3) standard deviation, (4) $F$, (5) $p$.

based on taking mental therapy. The results show no differentiation between those taking mental therapy or not.

Finally the differentiation of organizational commitment based on occupational experience is tabulated in table 15. According to the results, there is no statistically significant differentiation of organizational commitment based on occupational experience.

\section{Discussion}

A survey is conducted in this paper to test the main hypothesis that there is a relationship between organizational commitment and work life balance. The differentiation analysis of organizational commitment and work life balance based on personal characteristics are also analysed with this survey.

According to the regression analysis with the main hypothesis, organizational commitment can be explained with some individual properties of work life balance. The results show a statistically significant regression, with two of the four independent variables being significant. Overall, the main hypothesis of the research that there is a relationship between organizational commitment and work life balance is accepted.

The independent variables can also be analysed separately in the regression. The variables that are involved in the analysis are the effect of personal life to work, the effect of work to personal life, work life growth and the effect of working with husband/wife or other relative. Accordingly the variables the effect of personal life to work and the effect of working with husband/wife or other relative are not statistically significant. This means these variables are not explanatory for organizational commitment. According to the regression, the variables related with work life balance that are explanatory in organizational commitment are the effect of work to personal life and

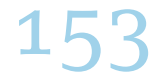


work life growth. The differentiation analysis of work life balance is also given for each individual personal characteristic that are explained in the research. These characteristics are number of children, level of income, number of clients, taking mental therapy, and occupational experience.

According to the first differentiation analysis, work life balance differentiates based on number of children. This is statistically significant only in work-life growth subfactor. The people with two children differentiate from the people with no children. This is to say that the people with two children have more work-life growth problem than the people with no children.

The differentiation analysis of work life balance is also available based on level of income. The results show that work life balance differentiates based on level of income for all of the four subfactors in the regression. These subfactors are the effect of personal life to work, the effect of work to personal life, work life growth and the effect of working with husband/wife or other relative. One selected finding in these regressions is that the 4001-6000 TL income group differentiates for all the subfactors with its mean being statistically higher. This shows that the most problematic level of income group that faces work life balance issues is the 4001-6000 TL.

Another differentiation analysis of work life balance is based on number of clients. Accordingly, the two subfactors that differentiate based on number of clients are the effect of work to personal life and the effect of working with husband/wife or other relative. In the regression with the effect of work to personal life, 29 or less number of clients group has significantly higher mean than three other number of clients groups. This means that accountants with 29 or less clients have most the effect of work to personal life problem. In the regression with the effect of working with husband/wife or other relative 30-35 number of clients group has statically the lowest mean. This means respondents with 30-35 clients have the least problems with the effect of working with husband/wife or other relative.

There is also an analysis for the differentiation of work life balance based on taking mental therapy. However the results show no meaningful differentiation between people taking mental therapy and those not taking it. The result is the same for all of the four subfactors analysed in the research for work life balance.

The final differentiation analysis of the work life balance is occupational experience. According to the analysis the two subfactors that differentiate based on occupational experience are the effect of personal life to work and work life growth. The people who have the 
most the effect of personal life to work and work life growth problem are 25 years and more occupational experience group according to the analysis.

There are also differentiation analyses of organizational commitment based on personal characteristics in the research. These characteristics include number of children, level of income, number of clients, taking mental therapy and occupational experience.

The first differentiation analysis of the organizational commitment is based on number of children. Accordingly, respondents with no children and with two children significantly differentiate from respondents with one child and three or more children. Another way of saying this is accountants with no children and with two children have more organizational commitment problem than accountant with one child and with three or more children.

Another differentiation analysis of the organizational commitment that is available in thesis is level of income. According to the results 2501-4000 TL level of income group has higher mean than 4001-6000 $\mathrm{TL}$ and $6001 \mathrm{TL}$ and more level of income groups. This means that 2501-4000 TL level of income group is less committed to the organization than 4001-6000 TL and 6001 TL and more level of income groups.

There is also the differentiation of organizational commitment based on number or clients in the research. According to the results, 30-35, 46-55, 56 and more number of clients groups differentiate from 29 or less and 36-45 number of clients groups. This indicates that accountants with 30-35, 46-55 and 56 and more clients have less organizational commitment than accountants with 29 or less or 36-45 number of clients groups.

Another differentiation analysis available in the research is the organizational commitment based on taking mental therapy. There is no statistically significant differentiation in organizational commitment between respondents taking mental therapy and respondents that do not take mental therapy.

The final differentiation analysis in the regression is organizational commitment based on occupational experience. However, there is also no statistically significant differentiation of organizational commitment based on occupational experience.

\section{Conclusion}

Accountants often need to work in environments where an intense schedule is required to have the required output by the deadline. This brings a problem of creating a balance between work and per- 
sonal life. Moreover information obtained what is learned theoretically before work doesn't guarantee success in career.

A survey is made for this research to 498 accountants who are members of Istanbul Chamber of Certified Public Accountants. A general evaluation of the research findings reveals that there is a significant effect of work life balance on organizational commitment. An unbalanced work and life of accountants leads to less organizational commitment. Therefore accountants need to be educated on policies that protect work life balance.

Only factor that is not significant which represent is the effect of personal life to work. According to the analysis the problems in their personal life don't significantly affect their commitment. However a significant increase in the working environment in terms of worklife balance would clearly increase the organizational commitment of the employees. This would increase the motivation of the employees and will make them stay in the organization.

For work life balance, the accountants with two children, middle income group, 29 or less clients, and 25 years and more occupational experience groups are some that experience work-life growth problem. Possible work-life balance precautions including flexible work hours, family leave programs, job sharing, reward schemes, and dependent care may be applied to accountants with a special focus on the critical groups found in the research.

For organizational commitment, the accountants with one child and three and more children, low income group, 30-35 and 46 and more age groups have less commitment. Proper organizational treatment and leadership should be applied to employees with a special focus on critical groups that appear in the research. This would increase the efficiency in the accounting department, increase employee motivation and duration of stay in the organization.

The big companies of the industry need to reconsider job descriptions and requirements which will improve the intense work load of the employees. There will be more time to motivate and focus on employees. The problems with managers can be discussed and resolved.

When the job requirements are revisited, the standards such as level of education can be increased. A more research oriented work environment can be built. These suggestions lead to a more career oriented rather than a money oriented approach by the accountants.

For future research, the relationship between work life balance and performance and motivation can be evaluated. Moreover a sur- 
vey with respondents from different cities and countries would benefit to analyse the cross cultural aspects of the research.

\section{References}

Ahuja, K. K., P. Padhy, and G. Srivastava. 2018. 'Performance Appraisal Satisfaction \& Organizational Commitment.' The Indian Journal of Industrial Relations 53 (4): 675-692.

Aksoy, C., H. I. Sengun, and Y. Yllmaz. 2018. 'Examination of the Relationship Between Job Satisfaction Levels and Organizational Commitments of Tourism Sector Employees: A Research in the South Eastern Anatolia Region of Turkey.' Electronic Journal of Social Sciences 17 (65): 356-365.

Aryee, S., T. Wyatt, and M. K. Min. 199o. 'Antecedents of Organizational Commitment and Turnover Intentions among Professional Accountants in Different Employment Settings in Singapore.' The Journal of Social Psychology 131 (4): 545-556.

Ayodtun, I. S., O. A. Maxwell, K. J. Oladele, F. O. Hezekiah, B. T. Taiye, and O. Olamide. 2018. 'Moderating Effect of Organizational Climate on a Task-Trait Leadership Orientation and Employee Commitment: The Nigerian Banking Experience.' Academy of Strategic Management Journal 17 (2): 1-6.

Balven, R., V. Fenters, D. S. Siegel, and D. Waldman. 2018. 'Academic Enterpreneurship: The Roles of Identity, Motivation, Championing, Education, Work Life Balance, and Organizational Justice.' Academy of Management Perspectives 32(1): 21-42.

Bloom, R., and W. J. Cenker. 2005. 'The Importance of Commitments: A Case Study of a Broken Promise.' Issues in Accounting Education 20 (4): 359-64.

Braun, S. and C. Peus. 2018. 'Crossover of Work Life Balance Perceptions: Does Authentic Leadership Matter?' Journal of Business Ethics 149 (4): 875-93.

Cannon, N. H., and D. N. Herda. 2016. 'Auditors' Organizational Commitment, Burnout and Turnover Intention: A Replication.' Behavioral Research in Accounting 28(2): 69-74.

Celis, N. J. 2018. 'A Case Study Approach in Understanding Organizational Commitment.' DLsu Business and Economics Review 27 (2): $88-118$.

Cetin, A. T., C. Kizil, and H. Zengin. 2013. 'Impact of Mentoring on Organizational Commitment and Job Satisfaction of Accounting-Finance Academicians Employed in Turkey.' Emerging Markets Journal 3(2). https://doi.org/10.5195/emaj.2013.40

Church, P. H. 2014. 'Assimilations of New Hires in Public Accounting.' Current Issues in Accounting 8 (2): A28.

George, D., and M. Mallery. 2010. spss for Windows Step by Step: A Simple Guide and Reference, 17.o Update. Boston, MA: Pearson.

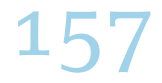


Gregson, T. 1992. 'An Investigation of the Casual Ordering of Job Satisfaction and Organizational Commitment in Turnover Models in Accounting.' Behavioral Research in Accounting 4:80-95.

Haider, S., S. Jabeen, and J. Ahmad. 2018. 'Moderated Mediation Between Work-Life Balance and Employeee Job Performance: The Role of Psychological Wellbeing and Satisfaction with Coworkers.' Journal of Work and Organizational Psychology 34 (1): 29-37.

Hart, M., J. Kremin, and W. R. Pasewark. 2017. 'Growing Up: How Internships Affect Students' Commitment and Long Term Intentions to Work in Public Accounting.' Issues in Accounting Education 32 (2): 47-63.

Herda, D. N., and J. J. Lavelle. 2013. 'Auditor Commitment to Privately Held Clients and Its Effect on Value-Added Audit Service.' Auditing: A Journal of Practise and Theory 32 (1): 113-37.

Karasar, N. (2014). Scientific Research Methods. Ankara: Nobel.

Ketchand, A. A., and J. R. Strawser. 2001. 'Multiple Dimensions of Organizational Commitment: Implications for Future Accounting Research.' Behavioral Research in Accounting 13:245-7.

Kanungo, R. 1982. 'Measurement of Job and Work Involvement.' Journal of Applied Psychology 67 (3): 341-9.

Kartal, H. 2015. 'The Factors That Affect Organizational Commitment and Application Analysis on the Relationship between Organizational Commitment and Concepts Such as Commitment to Work and Willingness to Resign.' Masters Thesis, Istanbul Technical University Institute for Science, Istanbul.

Küçükusta, D. 2007. 'The Influence of Work Life Balance on the Quality of Work Life in Tourism Industries.' Doctoral Dissertation, Dokuz Eylül University Institute for Social Sciences, Izmir.

Lapointe, E., and C. Vandenberghe. 2018. 'Examination of the Relationships between Servant Leadership, Organizational Commitment, and Voice and Anti-Social Behaviors.' Journal of Business Ethics 112 (1): $59-78$.

McManus, L., and N. Subramaniam. 2014. Organizational and Professional Commitment of Early Career Accountants: Do Mentoring and Organizational Ethical Climate Matter? Accounting and Finance 54, 1231.

Nizam, I., and C. Kam. 2018. 'The Determinants of Work-Life Balance in the Event Industry of Malaysia.' International Journal of Management, Accounting and Economics 5 (4): 1231-61.

Nasina, M. D., and K. P. P. Doris. 2011. 'The Workplace Spirituality and Affective Commitment Among Auditors in Big Four Public Accounting Firms: Does it Matter?' Journal of Global Management 2(2): 21626.

Oludayo, O. A., H. O. Falola, A. Obianuju, and F. Demilade. 2018. 'WorkLife Balance Initiative as a Predictor of Employees' Behavioral Out- 
comes.' Academy of Strategic Management Journal 17 (1). https:// www.abacademies.org/articles/Work-life-balance-initiative-as-a -predictor-of-employees-1939-6104-17-1-16o.pdf

Tabachnick, B. G., L. S. Fidell, and S. J. Osterlind. 2013. Using Multivariate Statistics. Boston, mA: Pearson.

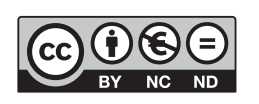

This paper is published under the terms of the Attribution-

NonCommercial-NoDerivatives 4.o International (CC BY-NC-ND 4.0)

License (http://creativecommons.org/licenses/by-nc-nd/4.o/). 